removed it, and its weight after removal was thirty-three pounds. It was not a "small fibroid enlargement of the nterus," but a well-marked example of the soft oedematous myoma. If Mr. Thornton has yet to learn that this disease is not arrested at the menopause, then he can accept the other horn of the dilemma. If this had been an isolated instance of its kind I should not have made use of it, but I shall have an opportunity soon of entering further into this aspect of the question. I am, Sir, yours truly,

LAWSON TAIT.

\section{ASSOCIATION OF FELLOWS OF THE ROYAL COLLEGE OF SURGEONS OF ENGLAND.}

\section{To the Editor of THE LANCET.}

SIR,-Do we want an Association of Fellows of the Royal College of Surgeons of England to consider "all questions affecting the interest of the Fellows and the government of the college?" I personally am not prepared to give a definite answer one way or the other. On the one hand, we have a Council whom we elect ourselves, who do not hold office for an indefinite time, and with whose action we are for the most part, I suppose, pretty well content; moreover, it has been clearly shown, even in later years, that the Council can be influenced by a powerfully expressed representation from the Fellows. On the other hand, it is no doubt a pleasant idea to bind the Fellows together into a body corporate, if that were possible, even if but little practical outcome came of such a union; as indeed the experience of the Convocation of the University of London would seem to render not improbable. But granted, for the sake of argument, that such an association is advisable, I would protest against its being tacked on as a sort of appendage to the British Medical Association, to which it is in no degree germane. It is notorions that a considerable number of Fellows never attend the meetings of the Association, and that many would always be prevented from doing so owing to the time of year that its meetings are held. It is difficult to see how such an Association could possibly be representative ; it is easy to understand how it might become cliquy, and therefore mischievous. If it is to be instituted, it would surely be better to hold it in London, aud at the same time that the election of Councillors and the Fellows' dinner take place. Why should it not be held on the same day, or if that were impossible, on the day before or after the election ?

I am, Sir, yours faithfully,

Dec. $20 \mathrm{th}, 1882$

RICKMAN J. GODLEE.

ON

EXAMTNING THE SPUTUM TN LUNG DISEASES OR THE BACTERIA OF TUBERCLE AS A MEANS OF DIAGNOSIS AND PROGNOSIS, AND SOME REMARKS ON STAINING.

\section{To the Editor of THE LANCET.}

SIR, - I have lately used as a means of diagnosis of tubercle an examination of the sputum for tubercle bacilli in all my cases of lung disease where grounds for suspicion existed, and I have found such means of diagnosis very valuable, in many cases solving the question where auscultation gave merely negative evidence. In two cases of apparently chronic pneumonia the discovery of bacilli in the sputum of one and not in the other led to a decided diagnosis and a variation of treatment, which was afterwards completely established by the subsequent progress of the cases, for in the one decided symptoms of phthisis became established in one lung. and in the other the lung trouble completely cleared up; and if the theory concerning the existence and connexion between these bacilli and tubercle be correct we cannot too highly estimate the value of the means that the existence of these bacilli affords of forming a correct diagnosis and a consequent prognosis, which is so anxiously looked for by the friesds in these cases. I have used the methods of Ehrlich and Heneage Gibbes, but find the latter's method the easier to foll $/ \mathrm{w}$, and at present use that solely. I prefer, however, that the secondary staining be done in methylene blue instead of chrysoidine; the surrounding tissue is rendered more distinct, whilst the contrust between the red bacteria and the blue is greater than between the red and brown of the chrysoidine.

I regret to say that when I first used either method my attempts were failures for a long time, and I began to almost give up in despair when it occurred tr me that at the time the methods were described the weather was very warm, and I discovered that the cover-glasses when in the magenta solution should be kept at a temperature of $100^{\circ} \mathrm{F}$. This I found ensured a uniform and deep crimson stain to the bacilli, so that in the sputa, examinsd previously with. out any result, I now found plenty of brcilli, and on obtain ing fresh sputa I found them at once. The bacilli of putrefaction are not stained by this process, but in specimens which have passed through the nitric tcid process and been washed, the putrefactive bacilli may be well shown by staining with a solution of gentian riolet, without affecting the tubercle bacilli-thus demonstracing the two kinds, and proving that they are not identical. I find also that for rapid work and purposes of diagassis, the cover-glass may, after staining in methylene blue and washing in water, be dried at once over a spirit-lamp flame, and mounted in a solution of Canada balsam, in chloroform and benzole, and examined at once. I have specimens prepared in this way two months ago in which the bacilli can be easily discovered by any one, even if not an experienced observer. They may be clearly seen with a No. 6 Hartnack, or even a quarter-inch, and with the former the spherical bodies within them are easily distinguished. I thus dispense with the washing in absolute alcohol and drying in the air. It is also necessary that the washing after staining should be done with distilled water. I find the dyes obtained from Martindale are quite stable, and my preparations have not faded at all as far as I can judge.

I am, Sir, your obedient servant

Engledue Prideaux, L.R.C.P. Lond., \&c. Wellington, Somerset, Dec. 1882.

\section{THE DETECTION OF THE TUBERCLE BACILLUS.}

To the Editor of THE LANCET.

SIR.-In your issue of last week you publish a long and somewhat incoherent letter from Dr. G. A. Heron, in which he impugns the veracity of my statements with regard to the new stain I have brought out for the bacillus of tubercle. Most of the objections raised in his letter were mentioned by him at the Medical Society's meeting, on the 4th of December, and refuted by me to the entire satisfaction, I think, of all present, saving of course Dr. Heron. He has, however, now done me the honour to review the various papers I have published on this subject, and to draw from them deductions not at all flattering to my truthfulness. I cannot allow these to pass without remarli. Immediately after the meeting of the Medical Society, Dr. Heron appears to have called on Mr. Beck, the agent or salesman of the Badesche Anilin Fabrik, and he gives the result of his interview. On referring to the price list of this company I find that they do not quote fuchsin in it; what then could they do when a customer asked for fuchsin, but sell him the nearest thing they had to it? Does this, however, prove that fuchsin and magenta are the same? As to the use of these names on the Contine it I can say notbing, but that they are used in the trade here to signify the saine thing is not correct. Let. Dr. Heron refer to the price lists of Messrs. Hopkins and Williams, Messrs. Jackson and Co., and Messrs. Becker and Co. He will there find magenta and fuchsin both quoted, the one (fuchsin) at double the price of the other. Does Dr. Heron suppose that firms of this standing are trying to defraud the public by selling the same substance nnder two names, and charging in the one case double what they do in the other? Dr. Heron admits in his letter that he koows nothing of the chemistry of the anilin compounds. He is therefore probably unaware that magenta is a very comprehensive term, and includes the hydrochloride, acerate, nitrate and sulphate of rosanilin. Does Dr. Heron think that all these will stain the tubercle bacillus? If so I would advise him to make some original investigations into the subject; he will then be able to speak with some authority on' the matter.

The facts of the case are these : When Ehrlich's method 